\title{
Connecting Places The Ecological Consequences of Dispersal in the Sea
}

BY STEVEN D. GAINES, BRIAN GAYLORD,

LEAH R. GERBER, ALAN HASTINGS, AND BRIAN P. KINLAN

Few traits are shared by all species of animals and plants. Movement is a noteworthy exception. Although many species seem permanently locked to a particular place, they inevitably move at some stage of their life cycles. The mobile phase can be adults, juveniles, or gametes. Species move for many reasons. Some move to seek food. Others move to avoid becoming food for someone else. Some move to seek favorable conditions. Others move to find a mate or an egg to fertilize. When these forms of movement occur over relatively short distances, they can play important roles in a wide range of ecological and evolutionary processes (Davidson et al., 2004). Much of marine ecology has focused on the dynamics and consequences of such local interactions.

Movement can also occur across much greater distances. As a result, processes that occur in one location may drive changes at distant sites or in other ecosystems through the ecological coupling of long-distance movement. Without knowledge about the pattern of these connections, it may be impossible to interpret the cause of changes observed at a given place. For example, northern elephant seals return to the same beach in central California (Año Nuevo) year after year to mate, give birth, and raise young. During the rest of the year, these individuals who interact so intensely on a small stretch of shore disperse to sites thousands of kilometers apart to feed (Le Boeuf et al., 2000). Males and females feed in different areas and have different diets (Le Boeuf et al., 2000). As a result, the dynamics of many ecological systems that are widely separated across the Pacific Ocean are coupled in complex ways through the activities of individuals who move between them. Technological advances in satellite-tracked tags have revealed the nature of these spatial connections for a growing range of species with highly mobile adults (e.g., Eckert and Stewart, 2001; Boyd et al., 2002; Boustany et al., 2002; Block et al., 2005). Given the large variability among species in their scales and 
patterns of adult movement, marine ecosystems each have a complex mosaic of connections with other places that may play key roles in population dynamics and species interactions (Gaines and Lafferty, 1995; Guichard et al., 2004; Wieters et al., in press).

Yet another form of movement has garnered considerable ecological attention-the dispersal of young away from their parents. There are many potential reasons for offspring to flee the site of their birth (e.g., reducing competition, limiting inbreeding, spreading risks of shared catastrophes, reducing exposure to the pathogens and predators of their parents; Strathmann, 1980, 1985; Palmer and Strathmann, 1981; Raimondi et al., 2004). Dispersal of young can also occur as a by-product of choices that have little to do with the explicit benefits of moving. This may be especially true of animals in the sea. Since seawater is commonly a nutritious broth spiced with plankton, one potential reproductive strategy is to produce enormous numbers of very small larvae that fend for themselves, finding food in the plankton (Thorson, 1950; Strathmann, 1985). Rather than having to provision each young with sufficient food to reach a large size, marine species can produce far more offspring with little nutritional investment in individual offspring.

The great majority of invertebrates and nearly all fish produce young that are microscopic and grow by feeding in the plankton. Larvae can spend days, weeks, or months drifting, eating, and growing in the plankton, and commonly increase in size by an order of magnitude. The potential fitness benefits from being able to produce minute young that can forage on their own, however, have a key side effect-larvae are dispersed away from their natal site as they drift and feed. Although their minute size and long residence period in the plankton have made it very difficult to track the dispersal of larvae directly, a variety of indirect measures of dispersal distances (e.g., genetic variation, rates of spread of exotic species, coupled biological and physical models; Grosberg and Cunningham, 2001; Palumbi, 2003; Kinlan and Gaines, 2003; Shanks et al., 2003; Cowen et al., 2006) suggest that larval dispersal can be large (see also Hedgecock et al., this issue and Werner et al., this issue). On average, offspring in the sea are typically dispersed much farther from their parents than offspring on land (Kinlan and Gaines, 2003; Kinlan et al., 2005). Just as with adult patterns of movement, there is also enormous variability in propagule dispersal distances among species (Figure 1). Scales of average propagule

\section{A SINGLE ISOLATED POPULATION}

Species' ranges commonly span large geographical areas (Stevens, 1989, 1996; Lester et al., 2007). The entire species population is invariably divided into a large number of subpopulations, whose dynamics are linked through movement. A full theoretical treatment of the dynamics of a population consisting of a series of interconnected subpopulations is not yet possible, but many of the issues that might contribute to population persistence and dynamics are understood. Even if we simplify the problem and focus on species that move only as larvae and are relatively sedentary as adults, understanding their population dynamics is a challenge from the views of both data and theory. A full understanding of the issues will eventually require interplay between both approaches. On the one hand, as we have noted, following the fate of dispersing larvae is very difficult. As a result, only limited informa-

\section{...nearly all marine ecosystems contain species with a rich diversity of life histories and patterns of movement that will drive an equally rich diversity of connectivity patterns.}

dispersal vary by more than six orders of magnitude, from meters to hundreds of kilometers. Even when average dispersal distances are large, however, some larvae can be retained quite close to their natal site (e.g., Swearer et al., 1999; Cowen et al., 2000; Jones et al., 2005;

Pineda et al., this issue). tion about dispersal is available in nearly all cases, though with animals that retain some kind of hard part that may record environmental signals, more information can be obtained (Zacherl et al., 2003; Warner et al., 2005; Levin, 2006, Thorrold et al., this issue). On the other hand, understanding the dynamics of a 
species that is widely dispersed in space is a challenging theoretical problem even if full information were available. Thus, the challenge is for the theory both to provide guidance in the face of limited data and to identify the vital data that need to be collected in the future.

Considerable progress toward understanding the complex dynamics of a spatially structured population can be made by starting with a simpler problem - the persistence of a single isolated population (Botsford et al., 2001; Hastings and Botsford, 2006). Studying persistence is equivalent to asking whether the spe- cies can grow when rare. In this case, we can ignore any density-dependent effects (nonlinearities). For the simple case of an isolated population, there are only two kinds of biological processes operating: the survival of settled larvae to adulthood and the subsequent production by these adults of larvae that ultimately settle back to the same location. An isolated population has no other potential sources of new recruits. Therefore, it will persist only if the probability that a larva released from this population will return to the same population, multiplied by the mean num-

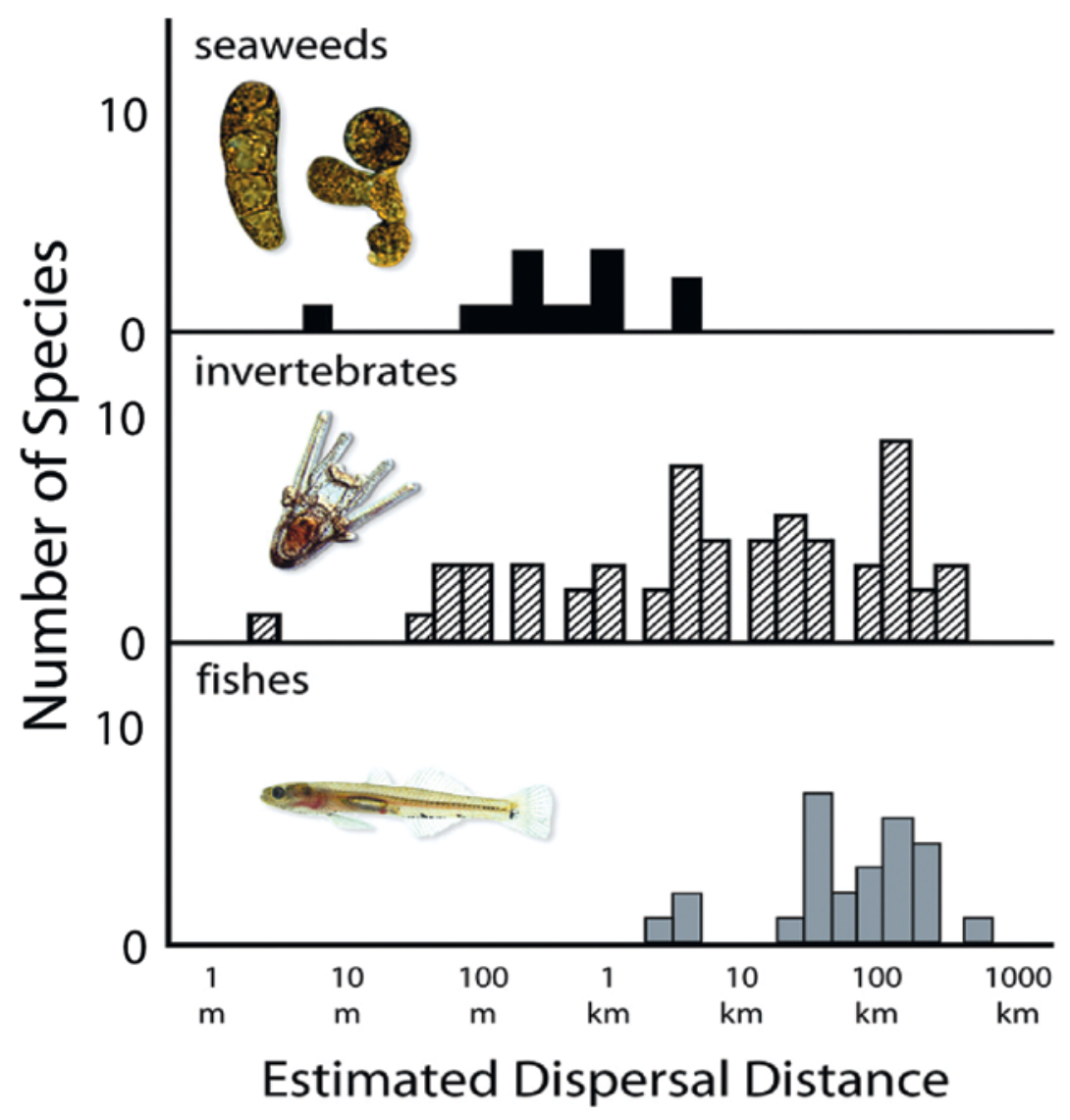

Figure 1. Estimates of average propagule (spores or larvae) dispersal distances for more than 100 species (redrawn from Kinlan and Gaines, 2003). Estimates are derived from genetic variation among populations using slopes from plots of genetic isolation by distance (Palumbi, 2003; Kinlan and Gaines, 2003; Kinlan et al., 2005). ber of larvae that a single settled larva can expect to produce in its lifetime, is greater than one. In other words, on average, a larva released by an adult at the site must ultimately lead to at least one more larva being released in the future. Otherwise, the population cannot persist. One part of this equation is relatively easy to determine, because it can be studied by looking only at the local subpopulation: survival and ultimate reproduction of new recruits. The second part, the likelihood that larvae return to the subpopulation of their birth, is much more difficult to measure, as larvae cannot typically be followed in the water column (but see Swearer et al., 1999; Jones et al., 1999, 2005;

Almany et al., 2007; Becker et al., 2007 for recent successes).

This simple approach might seem limited to cases of an isolated island or

STEVEN D. GAINES (gaines@lifesci.ucsb. edu) is Director, Marine Science Institute, University of California, Santa Barbara, CA, USA, and Associate Professor, Department of Ecology, Evolution, and Marine Biology, University of California, Santa Barbara, CA, USA. BRIAN GAYLORD is Assistant Professor, Bodega Marine Lab and Section of Evolution and Ecology, University of California, Davis, CA, USA. LEAH R. GERBER is Associate Professor, Ecology, Evolution and Environmental Science, School of Life Sciences, Arizona State University, Tempe, AZ, USA. ALAN HASTINGS is Professor, Department of Environmental Science and Policy, University of California, Davis, CA, USA. BRIAN P. KINLAN is Postdoctoral Scholar, Marine Science Institute, University of California, Santa Barbara, CA, USA. 
isolated protected area, but it is important to emphasize that isolated is defined in terms of the dispersal potential of the organism under consideration. For example, for species like seaweeds, abalone, or many corals, whose offspring have fairly limited dispersal, even nearby reefs could be considered isolated from each other (Kinlan and Gaines, 2003).

The focus on settings with no ecological connectivity serves to emphasize that it is the overall return to suitable habitat of dispersing larvae that is the key to persistence. The heuristic model sets the stage for thinking about how population dynamics change when there are multiple subpopulations with different degrees and patterns of connectivity.

\section{A FRAMEWORK FOR \\ EXPLORING ECOLOGICAL CONNECTIVITY}

Movement at any life stage connects places. As a result, the population dynamics of a species at any single location may depend on processes and interactions that occur at distant locations. Figure 2 depicts a framework that explicitly includes the possibility for movement of individuals from one site or habitat to another in different life stages (Gerber et al., 2005). This framework is helpful in conceptualizing the role of life history and dispersal for different species.

Dispersal mechanisms and their timing have different consequences for dif- ferent species. For many marine invertebrates, the movement of larvae is the primary mechanism of dispersal, while many megavertebrates move as juveniles or adults (Gerber and Heppell, 2004). This idea can be formalized as a matrix population model that incorporates the movement from one life stage to another for a given species within and between two or more sites (Gerber et al., 2005). For example, one can consider dispersal rates among species or among sites with different oceanographic settings. It is also informative to model these varying dispersal rates for species that have different dispersal timing. For example, for gray whales and turtles, connections between sites may be modeled as adult
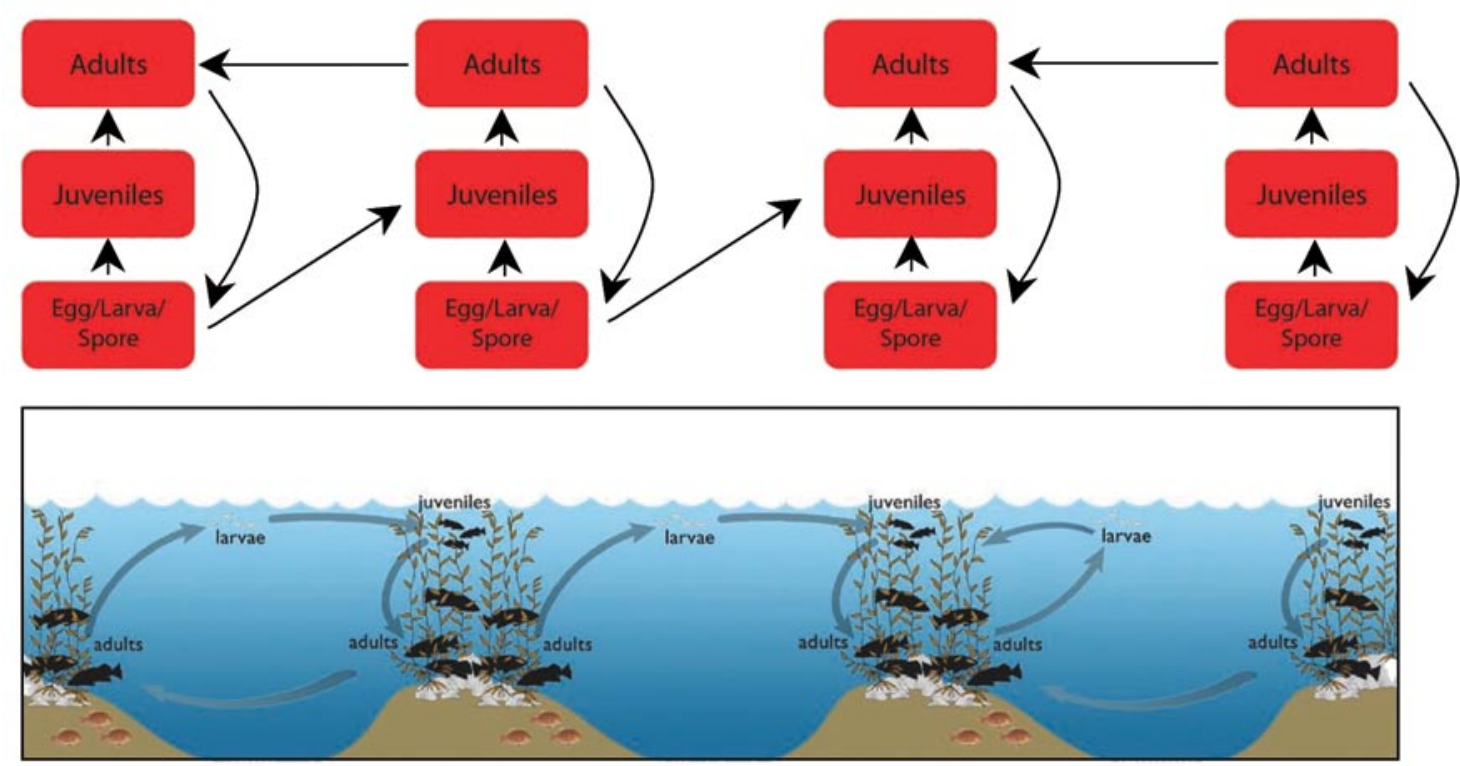

Figure 2. Conceptual framework for considering dispersal in simple demographic models. The model includes transition probabilities for general migration, ontogenetic shifts, and larval dispersal among sites arrayed along a coastline (Gerber et al., 2005). Species differ dramatically in the scales and spatial patterns of movement that connect sites. They also differ in where movement occurs within the life cycle. The matrix of sites and life stages with probabilities of movement between them forms the basis for modeling the dynamics of spatially structured populations. This simplified schematic highlights a scenario with multiple distinct patches (e.g., separate reefs on distinct islands, marine reserves versus unprotected sites, or multiple estuaries), illustrating a situation in which the mechanism of exchange can be (a) recruitment of larvae or newborns, (b) random exchange ("spillover") among adults and/or juvenile life stages, or (c) an ontogenetic shift in habitat use between sites. This generic model allows explicit incorporation of any or all of these transition probabilities. 
movement; for sea urchins and groupers, connectivity may be modeled as dispersal of young away from their natal site.

Population growth rates that arise from each of these different dispersal scenarios can then be evaluated to understand the extent to which different dispersal rates and connection patterns influence the dynamics of species in different ecological settings and under different management actions, such as fisheries regulations or protection utilizing marine reserves (Gerber et al., 2005). This approach can also be used to understand the importance of the timing of dispersal. One can then examine how dispersal as larvae, juveniles, adults, or other stages in the life cycle influences population growth rates for species with different demographic rates. This can be accomplished by applying standard demographic sensitivity analysis (Caswell, 2001; Gerber and Heppell, 2004) that includes distinct spatial areas linked by dispersal. Such analyses highlight the relative importance of dispersal at different life stages for species with varying life histories (e.g., larval dispersal in marine invertebrates versus adult movement for sea turtles versus larvae and adults in holoplankton such as copepods).

The ecological consequences of different scales and patterns of connectivity are profound and diverse. We briefly illustrate the broad range of ecological effects by highlighting three cases: (1) multiple subpopulations with weak connections, (2) multiple populations with strong connections, and (3) barriers to connectivity.
MULTIPLE POPULATIONS WITH WEAK CONNECTIONS

Many subpopulations would likely go and stay extinct if they were not connected demographically to other subpopulations. With the movement of propagules, larvae, or adults, subpopulation extinctions need not be permanent. Sites can be recolonized by the arrival of new individuals from other sites. If the connectivity among subpopulations is relatively weak because of limited movement, the species can be characterized by classical metapopulation "patch model" dynamics (Levins, 1969; Hanski ,1998)sites undergo stochastic patterns of extinctions and recolonizations. Classical metapopulation dynamics have been widely explored in terrestrial habitats (Hanski, 1998), but marine examples are rare by comparison (Spight, 1974, 1981, 1982; Kritzer and Sale, 2006).

One of the best marine examples comes from decades of records of the abundance of the giant kelp, Macrocystis pyrifera (Figure 3a), along the coasts of California, USA, and Baja California, Mexico (Figure 3b) (Kinlan, 2007; Reed et al., 2006). Macrocystis forms large beds that provide habitat for a rich diversity of seaweeds, invertebrates, fish, mammals, and birds. Kelp forests, however, are notoriously susceptible to the episodic occurrence of large waves associated with major storms, poor growing conditions with low nutrients and warm temperatures, and/or grazer outbreaks, all of which can cause occasional but massive localized mortality (Dayton and Tegner, 1984, 1989; Ebeling et al., 1985; Edwards, 2004; Reed et al., 2006). Time series of the coverage of kelp canopy as a function of position along the coast
(Figure 3b) therefore exhibit large fluctuations as individual subpopulations blink in and out of existence. During intervals between disturbance events, local reproduction dominates and the dynamics of individual kelp forests operate mostly independently. After a kelp bed has been driven locally extinct, however, connections to other beds become critical. It is only through the delivery of new spores or individuals produced elsewhere, via the relatively weak links of longer-distance dispersal, that the nowextinct kelp forest can recover.

Studies of Macrocystis kelp beds across its entire geographic range showed that extinction rates vary by two orders of magnitude across sites with the peaks of site extinction approaching 0.3 per month (Reed et al., 2006). Recolonization of sites is presumed to occur largely through the dispersal of spores that are moved by ocean currents. Recolonization rates following extinction vary by an order of magnitude among sites with isolated and small reefs having the lowest probabilities of recolonization following bed extinction (Reed et al., 2006). The resulting metapopulation dynamics are readily visible in Figure 3b. Following the dynamics of any site through time shows that kelp beds repeatedly go extinct and are subsequently recolonized. Some disturbances, such as the 1998 El Niño (month 360 in Figure 3b), generate strong synchrony in extinction across a large number of sites. Other extinction events are more stochastic in space and time, creating relatively independent dynamics across sites. The extent and spatial pattern of connectivity by spore dispersal is critical in driving these largescale patterns of population change. 


\section{MULTIPLE POPULATIONS WITH} STRONG CONNECTIVITY

The classic spatially structured metapopulation dynamics seen in kelp beds with stochastic aspects of extinction and recolonization is unlikely to occur in most marine species, because their dispersal is too large and local extinctions are less common. If subpopulations are more frequently and distantly connected, subpopulations do not go extinct, even in the face of periodic local disturbances. Frequent new colonists prevent local extinctions and couple the population dynamics at one site to the production of young at other sites.

Initial considerations of the ecological consequences of strong connectivity over moderate to large distances treated local subpopulations as being "open" populations. The arriving number of larvae or spores was independent of local reproduction and was presumed to be derived from a pool of propagules of unspecified origin (e.g., Gaines and Roughgarden, 1985; Roughgarden et al., 1988; Caley et al., 1996). Although this approach had heuristic value and spawned a surge of focus on the supply-side ecology of marine population and community patterns (Roughgarden et al., 1988; Underwood and Keough, 2001), it ignored the additional key role of the spatial pattern of connectivity.
The absence of subpopulation extinctions does not mean that patterns of connectivity do not create spatial structure. Especially in marine species with planktonic larvae and sedentary adults, local population dynamics depend to a great extent on the arriving larvae. Hastings and Botsford (2006) developed a model that focuses on the interchange of larvae among the connected populations and obtained a useful heuristic description of a condition for persistence that extends the single isolated patch criterion presented above. Essentially, the condition for persistence can be understood in terms of loops of connectivity and production (but see the original
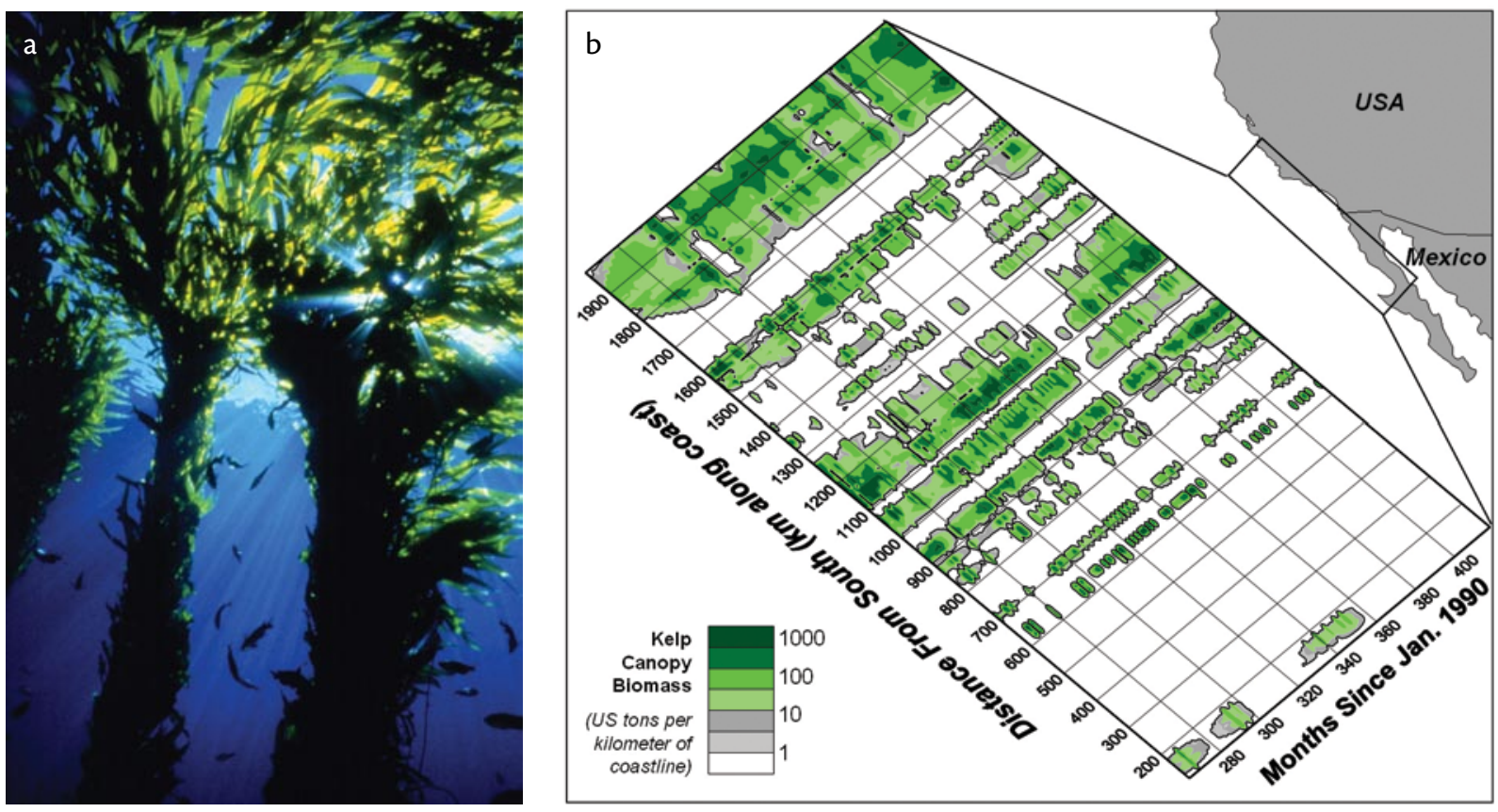

Figure 3. (a) Photograph of the giant kelp, Macrocystis pyrifera. Image @Mark Conlin, used with permission (b) Dynamics of giant kelp along the coasts of the western United States and Mexico (inset, top right), based on monthly aerial surveys of surface canopy biomass conducted by ISP Alginates, Inc. from 1990-2002 (Reed et al., 2006; Kinlan, 2007). Colored contours indicate the relative biomass of kelp forest canopy adjacent to the mainland coast. White patches indicate times and places where kelp subpopulations were not visible from the surface; since giant kelp grows rapidly, periods of six months or longer in which no surface kelp was observed represent likely local extinctions (Reed et al., 2006). Distances are measured in a coastline-following coordinate system, and represent the cumulative distance measured along the 1:250,000 World Vector Shoreline from a defined point in the south (near Punta Eugenia, Baja California del Sur, Mexico) to the north (near Carmel, California, USA). Modified, with permission, from Kinlan (2007) and Reed et al. (2006) 


\section{As we expand our ability to study patterns of connectivity with greater resolution within single species, we will be poised for more rapid exploration of their community and ecosystem level consequences.}

paper for complications). The simplest loops involve two locations - where larvae are released from one location and settle and survive in a second location to produce adults that release larvae that end up back in the first location. If there are loops over which, on average, an individual produces more than one individual that eventually ends up back in the location of the original individual, then the population will persist. This criterion has a nice heuristic description, but perhaps the major insight for marine systems is that it emphasizes the need to understand dispersal at a level that has rarely been achieved. However, of more immediate use, this result shows that sites that are merely sources (from which larvae are widely dispersed) or that are only good locations for settling are not enough for persistence-only locations that both receive and disperse larvae play a vital role. These general properties can sometimes be deduced from ocean currents, as we discuss below.

\section{A different approach to persistence} was undertaken by Botsford et al. (2001) who considered the simpler situation of equally spaced, equally sized stretches of suitable habitat placed uniformly along a coastline with larvae settling in a symmetric pattern around the point of release. In this case, a persistence criterion was defined essentially under an assumption of uniform production rates. Here, either a sufficient fraction of the habitat had to be suitable if persistence arose from network considerations, or each individual suitable location had to be large enough relative to the mean dispersal distance of the focal species.

We have built up to an understanding of the role of connectivity in simple cases that are somewhat more complex than the single isolated patch, while noting that other factors, such as year-to-year variability or interactions among multiple species, will introduce further complications. Thus, the work of Hastings and Botsford (2006) was a useful first step focusing on the interplay between dispersal and local production, but much more needs to be done, especially in matching theory to the kinds of variability observed in data and matching data to theory. One way to gain insights into connectivity and persistence is through expanded studies of ocean currents and their projected role in movement (Cowen et al., 2000, 2006; Siegel et al., 2003 , in press). Eventually, integrated studies using a variety of approaches (ocean currents, genetics, studies of invasive species, otolith studies) will allow further understanding of connectivity (Levin, 2006).

\section{BARRIERS TO CONNECTIVITY}

Just as ocean currents can facilitate connectivity among disjunct populations in the sea, they can also create leaky barriers to dispersal. These barriers are not absolute in the sense of large bodies of water or mountain ranges that prevent movement of terrestrial species. Rather, they act more subtly, retarding movement in one direction versus another (Gaylord and Gaines, 2000). For populations that are open to an appreciable degree, this feature can have important effects on relative rates of emigration and immigration, and thereby on population persistence, distributional patterns, and species range limits. 
The ability of circulation features to alter the balance between population inputs and losses provides the underpinnings of an ecological dispersal barrier. Along many continental margins, there are dominant currents that create asymmetry in directional transport. Although mixing processes cause movement of larvae against the dominant flow, in some cases sufficient residual asymmetry persists to have population consequences. The response of a given population relies on the relative strengths of the advective currents and mixing processes, and on the demographic state of the population (i.e., whether population inputs greatly exceed those required for persistence, such that density-dependent factors operate strongly, or whether population inputs are on the cusp relative to population losses). In the latter case, patterns of ocean circulation may play an especially relevant role in setting distributional patterns (Cowen, 1985; Cowen et al., 2000, 2006; Guizien et al., 2006; Aiken et al., 2007).

Worldwide, distributional limits in many organisms cluster at shoreline locations where there are oceanographic discontinuities (e.g., convergent or divergent currents, or persistent eddies; Wares et al., 2001; Gaines et al., in press). These so-called biogeographic boundaries are often assumed to arise due to the strong gradients in water properties (especially temperature) that accompany the collisions of different water masses. However, these oceanographic discontinuities also alter the directional character and intensities of mixing of waters transporting the larvae of adjacent populations. As shown in a generalized context by Gaylord and Gaines (2000), discontinui- ties associated with colliding currents, regions of strong divergence, or stable zones of recirculation driven by coastal topography have the potential to create considerable asymmetry in larval transport. As outlined above, this asymmetry can in turn result in substantial shifts in relative rates of emigration and immigration over relatively short stretches of shoreline. If species in these areas are vulnerable to subpopulation extinction with small or modest changes in rates of propagule or larval input, their population densities may abruptly decline to zero over the same stretches of coastline. In such situations, the leaky dispersal barriers associated with the ocean discontinuities create the observable clusters of range boundaries identified with biogeographic boundaries.

\section{ECOSYSTEMS INCLUDE A DIVERSITY OF CONNECTIONS} Understanding the dynamics of single species with multiple connected subpopulations still remains a difficult challenge in its own right. Yet, nearly all marine ecosystems contain species with a rich diversity of life histories and patterns of movement that will drive an equally rich diversity of connectivity patterns. For example, the kelps of Figure 3 release propagules near the seafloor that remain viable for only a couple of days. These propagules are therefore influenced by the hydrodynamics of near-bottom mixing as well as larger-scale ocean currents. The result is that distributions of dispersal distance become highly skewed, with many propagules settling within the confines of the source subpopulation (i.e., over scales of meters; Dayton, 1985; Santileces, 1990), but with an appreciable subset also settling at far greater distances (Gaylord et al., 2002, 2006). These latter propagules, those associated with the longer-distance tail of the distribution, provide the means for exchange among subpopulations that may be separated by hundreds of meters to kilometers. Other species that strongly interact with kelps, such as sea urchins, are characterized by quite different dispersal distributions. Their more routine long-distance dispersal couples sites much further apart, and as a result, larval input at any given site is mostly uncoupled from local production and instead reflects regional-scale production from many subpopulations.

Coastal marine ecosystems have served as a rich laboratory for studying species interactions (Connell, 1961; Paine, 1966; Estes et al., 1978; Duggins, 1980), but few of the studies undertaken consider how connections with other locations alter the dynamics. Although the effects on species interactions of external inputs of food and nutrients are well documented (e.g., Polis and Hurd, 1996), the effects of exogenous inputs of juveniles have received less direct experimental attention (Gaines and Lafferty, 1995; Wieters et al., in press). Do predator/prey dynamics differ when the patterns and scales of connectivity differ between predator and prey? How does the outcome of competition depend on the nature of connections with other subpopulations for the two competing species? These community-level questions regarding the role of connectivity have received theoretical attention for interactions between two marine species (Warner and Chesson, 1985; McLaughlin and Roughgarden, 1992; Gaines and 
Lafferty, 1995; McCauley et al., 1996; de Roos et al., 1998; Navarrete et al., 2000), and the role of connectivity in metacommunity dynamics has received extensive theoretical discussion in analyses of terrestrial communities (Mouquet and Loreau, 2002; Leibold et al., 2004), but empirical studies in the sea remain understandably rare (Wieters et al., in press). Even the extensive theoretical attention to the role of connectivity in the design of networks of marine reserves (Botsford et al., 2001; Sala et al., 2002; Gaines et al., 2003; Gaylord et al., 2005), an inherently multispecies issue, has focused almost entirely on single species dynamics with no interactions (but see Guichard et al., 2004; Baskett et al., 2007). As we expand our ability to study patterns of connectivity with greater resolution within single species, we will be poised for more rapid exploration of their community and ecosystem level consequences.

\section{ACKNOWLEDGEMENTS}

Support for this work was provided by the National Science Foundation, Andrew W. Mellon Foundation, Gordon and Betty Moore Foundation, David and Lucille Packard Foundation, and Pew Charitable Trust. שd

\section{REFERENCES}

Aiken, C.M., S.A. Navarrete, M.I. Castillo, and J.C. Castilla. 2007. Along-shore larval dispersal kernels in a numerical ocean model of the central Chilean coast. Marine Ecology Progress Series 339:13-24.

Almany, G.R., M.L. Berumen, S.R. Thorrold, S. Planes, and G.P. Jones. 2007. Local replenishment of coral reef fish populations in a marine reserve. Science. 316:742-745.

Baskett, M.L., F. Micheli, and S.A. Levin. 2007. Designing marine reserves for interacting species: Insights from theory. Biological Conservation 137:163-179.
Becker, B.J., L.A.Levin, F.J.Fodrie, and P.A.McMillan. 2007. Complex larval connectivity patterns among marine invertebrate populations. Proceedings of the National Academy of Sciences of the United States of America 104:3,267-3,272.

Block B.A, S.L.H. Teo, A. Walli, A. Boustany, M.J.W. Stokesbury, C.J. Farwell, K.C. Weng, H. Dewar, and T.D. Williams. 2005. Electronic tagging and population structure of Atlantic bluefin tuna. Nature 434:1,121-1,127.

Botsford, L., A. Hastings, and S.D. Gaines. 2001. Dependence of sustainability on the configuration of marine reserves and larval dispersal distance. Ecology Letters 4:144-150.

Boustany, A.M., S.F. Davis, P. Pyle, S.D. Anderson, B.J. Le Boeuf, and B.A. Block. 2002. Satellite tagging: Expanded niche for white sharks. Nature 415:35-36.

Boyd, I.L., I.J. Staniland, and A.R. Martin. 2002. Distribution of foraging by female Antarctic fur seals. Marine Ecology Progress Series 242:285-294.

Caley, M.J., M.H. Carr, M.A. Hixon, T.P. Hughes, G.P. Jones, and B.A. Menge. 1996. Recruitment and the local dynamics of open marine populations. Annual Review of Ecology and Systematics 27:477-500.

Caswell H. 2001. Matrix Population Models: Construction, Analysis, and Interpretation. Sinauer Associates, Inc., Sunderland, MA. 722 pp.

Connell, J.H. 1961. The influence of interspecific competition and other factors on the distribution of the barnacle Chthamalus stellatus. Ecology 42:710-723.

Cowen, R.K. 1985. Large scale pattern of recruitment by the labrid, Semicossyphus pulcher: Causes and implications. Journal of Marine Research 43:719-742.

Cowen, R.K., K.M.M. Lwiza, S. Sponaugle, C.B. Paris, and D.B. Olson. 2000. Connectivity of marine populations: Open or closed? Science 287:857-859.

Cowen, R.K., C.B. Paris, and A. Srinivasan. 2006. Scaling of connectivity in marine populations. Science. 311:522-527.

Davidson, I.C., A.C. Crook, and D.K.A. Barnes. 2004. Quantifying spatial patterns of biodiversity: Is movement important? Marine Ecology 25:15-34.

Dayton, P.K. 1985. Ecology of kelp communities. Annual Review of Ecology and Systematics 16:215-245.

Dayton, P.K., and M.J. Tegner. 1984. Catastrophic storms, El Niño and patch stability in a southern California kelp community. Science. 224:283-285.

Dayton, P.K., and M.J. Tegner. 1989. Bottoms beneath troubled waters: Benthic impacts of the 1982-1984 El Niño in the temperate zone. Pp. 433-472 in Global Ecological Consequences of the 1982-83 El Niño-Southern Oscillation. P.W. Glynn, ed., Elsevier, Amsterdam.

de Roos, A.M., E. McCauley, and W.G. Wilson. 1998. Pattern formation and the spatial scale of interaction between predators and their prey. Theoretical
Population Biology 53:108-130.

Duggins, D.O. 1980. Kelp beds and sea otters-an experimental approach. Ecology 61:447-453.

Ebeling, A.W., D.R. Laur, and R.J. Rowley. 1985. Severe storm disturbances and reversal of community structure in a southern California kelp forest. Marine Biology 84:287-294.

Eckert, S.A., and B.S. Stewart. 2001. Telemetry and satellite tracking of whale sharks, Rhincodon typus, in the Sea of Cortez, Mexico, and the north Pacific Ocean. Developments in Environmental Biology of Fishes 20:299-308.

Edwards, M.S. 2004. Estimating scale-dependency in disturbance impacts: El Niños and giant kelp forests in the northeast Pacific. Oecologia 138:436-447.

Estes, J.A., N.S. Smith, and J.F. Palmisano. 1978. Sea otter predation and community organization in Western Aleutian Islands, Alaska. Ecology 59:822-833.

Gaines, S.D, B.Gaylord, and J.Largier. 2003. Avoiding current oversights in marine reserve design. Ecological Applications 13:S32-S46.

Gaines, S.D., and K.D. Lafferty. 1995. Modeling the dynamics of marine species: The importance of incorporating larval dispersal. Pp. 389-412 in Ecology of Marine Invertebrate Larvae. L.R. McEdward, ed., CRC Press, Boca Raton, FL.

Gaines, S.D., S. Lester, G. Eckert, B.P. Kinlan, R. Sagarin, and B. Gaylord. In press. Dispersal and geographic ranges in the sea. In Marine Macroecology. J. Witman and K. Roy, eds, University of Chicago Press, Chicago, IL.

Gaines, S.D., and J. Roughgarden. 1985. Larval settlement rate: A leading determinant of structure in an ecological community of the rocky intertidal zone. Proceedings of the National Academy of Sciences of the United States of America 82:3,707-3,711.

Gaylord, B., and S.D. Gaines. 2000. Temperature or transport? Range limits in marine species mediated solely by flow. American Naturalist 155:769-789.

Gaylord, B., S.D. Gaines, D.A. Siegel, and M.H. Carr. 2005. Marine reserves exploit population structure and life history in potentially improving fisheries yields. Ecological Applications 15:2,180-2,191.

Gaylord, B., D.C. Reed, P.T. Raimondi, L.Washburn, and S.R. McLean. 2002. A physically based model of macroalgal spore dispersal in the wave and current-dominated nearshore. Ecology 83:1,239-1,250.

Gaylord, B., D.C. Reed, P.T. Raimondi, and L. Washburn. 2006. Macroalgal spore dispersal in coastal environments: Mechanistic insights revealed by theory and experiment. Ecological Monographs 76:481-502.

Gerber, L.R., and S.S. Heppell. 2004. The use of demographic sensitivity analysis in marine species conservation planning. Biological Conservation 120:121-128.

Gerber, L.R., S.S. Heppell, F. Ballantyne, and E. Sala. 2005. The role of dispersal and demography in determining the efficacy of marine reserves. 
Canadian Journal of Fisheries and Aquatic Sciences 62:863-871

Grosberg, R., and C.W. Cunningham. 2001. Genetic structure in the sea: From populations to communities. Pp. 61-84 in Marine Community Ecology. M.D. Bertness, S.D. Gaines, and M.E. Hay, eds, Sinauer Associates, Inc., Sunderland, MA.

Guizien, K., T. Brochier, J.C. Duchene, B.S. Koh, and P. Marsaleix. 2006. Dispersal of Owenia fusiformis larvae by wind-driven currents: Turbulence, swimming behavior and mortality in a three-dimensional stochastic model. Marine Ecology Progress Series 311:47-66.

Guichard, F., S.A. Levin, A. Hastings, and D. Siegel. 2004. Toward a dynamic metacommunity approach to marine reserve theory. BioScience $54: 1,003-1,011$.

Hanski, I. 1998. Metapopulation dynamics. Nature 396:41-49.

Hastings, A., and L.W. Botsford. 2006. Persistence of spatial populations depends on returning home. Proceedings of the National Academy of Sciences of the United States of America 103:6,067-6,072.

Jones, G.P., M.J. Milicich, M.J. Emslie, and C. Lunow. 1999. Self-recruitment in a coral reef fish population. Nature 402:802.

Jones, G.P., S. Planes, S.R. Thorrold. 2005. Coral reef fish larvae settle close to home. Current Biology $15: 1,314-1,318$

Kinlan, B.P., and S.D. Gaines. 2003. Propagule dispersal in marine and terrestrial environments: A community perspective. Ecology 84:2,007-2,020.

Kinlan, B.P., S.D. Gaines, and S.E. Lester. 2005. Propagule dispersal and the scales of marine community process. Diversity and Distributions 11:139-148.

Kinlan, B.P. 2007. Quantitative spatial ecology of benthic ecosystems in temperate coastal upwelling zones. Ph.D. Dissertation, University of California, Santa Barbara, California, USA.

Kritzer, J.P., and P.F. Sale, eds. 2006. Marine Metapopulations. Academic Press, San Diego, CA. 576 pp.

Le Boeuf, B.J., D.E. Crocker, D.P. Costa, S.B. Blackwell, P.M. Webb, and D.S. Houser. 2000. Foraging ecology of northern elephant seals. Ecological Monographs 70:353-382.

Leibold, M.A., M. Holyoak, N. Mouquet, P. Amarasekare, J.M. Chase, M.F. Hoopes, R.D. Holt, J.B. Shurin, R. Law, D. Tilman, M. Loreau, and A. Gonzalez. 2004. The metacommunity concept: A framework for multi-scale community ecology. Ecology Letters 7:601-613.

Lester, S.E., B.I. Ruttenberg, S.D. Gaines, and B.P. Kinlan. 2007. The relationship between dispersal ability and geographic range size. Ecology Letters 10:745-758.

Levin, L.A. 2006. Recent progress in understanding larval dispersal: New directions and digressions. Integrative and Comparative Biology 46:282-297.

Levins, R. 1969. Some demographic and genetic conse- quences of environmental heterogeneity for biological control. Bulletin of the Entomological Society of America 15:237-240.

McCauley, E., W.G. Wilson, and A.M. de Roos. 1996. Dynamics of age-structured predator-prey populations in space: Asymmetrical effects of mobility in juvenile and adult predators. Oikos 76:485-497.

McLaughlin, J.F., and J. Roughgarden. 1992. Predation across spatial scales in heterogeneous environments. Theoretical Population Biology 41:277-299.

Mouquet, N., and M. Loreau. 2002. Coexistence in metacommunities: The regional similarity hypothesis. American Naturalist 159:420-426.

Navarrete, S.A., B.A. Menge, and B.A. Daley. 2000. Species interactions in intertidal food webs: Prey or predation regulation of intermediate predators? Ecology 81:2,264-2,277.

Paine, R.T. 1966. Food web complexity and species diversity. American Naturalist 100:65-75.

Palmer, A.R., and R.R. Strathmann. 1981. Scale of dispersal in varying environments and its implications for life histories of marine invertebrates. Oecologia 48:308-318.

Palumbi, S.R. 2003. Population genetics, demographic connectivity and the design of marine protected areas. Ecological Applications 13:S146-S158.

Polis, G.A., and S.D. Hurd. 1996. Linking marine and terrestrial food webs: Allochthonous input from the ocean supports high secondary productivity on small islands and coastal land communities. American Naturalist 147:396-423.

Raimondi, P.T., D.C. Reed, B.Gaylord, and L.Washburn. 2004. Effects of self-fertilization in the giant kelp, Macrocystis pyrifera. Ecology 85:3,267-3,276.

Reed, D.C., B.P. Kinlan, P.T. Raimondi, L. Washburn, B. Gaylord, and P.T. Drake. 2006. A metapopulation perspective on patch dynamics and connectivity of giant kelp. Pp. 352-386 in Marine Metapopulations. J.P. Kritzer and P.F. Sale, eds, Academic Press, San Diego, CA.

Roughgarden, J., S.D. Gaines, and H. Possingham. 1988. Recruitment dynamics in complex life cycles. Science 241:1,460-1,466.

Sala, E., O. Aburto-Oropeza, G. Paredes, I. Parra, J.C. Barrera, and P.K. Dayton. 2002. A general model for designing networks of marine reserves. Science 298:1,991-1,993.

Santelices, B. 1990. Patterns of reproduction, dispersal and recruitment in seaweeds. Oceanography and Marine Biology Annual Review 28:177-276.

Shanks, A.L., B.A. Grantham, and M.H. Carr. 2003. Propagule dispersal distance and the size and spacing of marine reserves. Ecological Applications 13: S159-S169.

Siegel, D., B.P. Kinlan, B. Gaylord, and S.D. Gaines. 2003. Lagrangian descriptions of marine larval dispersion. Marine Ecology Progress Series 260:83-96.

Siegel, D.A., S. Mitarai, C.J. Costello, S.D. Gaines, B.E. Kendall, R.R. Warner, and K.B. Winters. In press. The stochastic nature of larval connectivity among near- shore marine populations. Proceedings of the National Academy of Sciences of the United States of America.

Spight, T.M. 1974. Sizes of populations of a marine snail. Ecology 55:712-729.

Spight, T.M. 1981. How three rocky shore snails coexist on a limited food resource. Researches on Population Ecology 23:245-261.

Spight, T.M. 1982. Population sizes of two marine snails with a changing food supply. Journal of Experimental Marine Biology and Ecology 57:195-217.

Stevens, G.C. 1989. The latitudinal gradient in geographical range: How so many species coexist in the tropics. American Naturalist 133:240-256.

Stevens, G.C.1996. Extending Rapoport's rule to Pacific marine fishes. Journal of Biogeography 23:149-154.

Strathmann, R.R. 1980. Why does a larva swim so long? Paleobiology 6:373-376.

Strathmann, R.R. 1985. Feeding and nonfeeding larval development and life-history evolution in marine invertebrates. Annual Review of Ecology and Systematics 16:339-361.

Swearer, S.E., J.E. Caselle, D.W. Lea, and R.R. Warner. 1999. Larval retention and recruitment in an island population of a coral-reef fish. Nature 402:799-802.

Thorson, G. 1950. Reproductive and larval ecology of marine bottom invertebrates. Biological Reviews 25:1-45.

Underwood, A.J., and M.J. Keough. 2001. Supplyside ecology: The nature and consequences of variations in recruitment of intertidal organisms. Pp. 183-200 in Marine Community Ecology. M.D Bertness, S.D. Gaines, and M.E. Hay, eds, Sinauer Associates, Inc., Sunderland, MA.

Wares, J., S.D. Gaines, and C. Cunningham. 2001. A comparative study of asymmetric migration events across a marine biogeographic boundary. Evolution. 55:295-306.

Warner, R.R., and P.L. Chesson. 1985. Coexistence mediated by recruitment fluctuations: A field guide to the storage effect. American Naturalist 125:769-787.

Warner, R.R., S.E. Swearer, J.E. Caselle, M. Sheehy, and G. Paradis. 2005. Natal trace-elemental signatures in the otoliths of an open-coast fish. Limnology and Oceanography 50:1,529-1,542.

Wieters, E., S.D. Gaines, S.A. Navarrete, C.A. Blanchette, and B.A. Menge. In press. Scales of dispersal and the biogeography of marine predator-prey interactions. American Naturalist.

Zacherl, D.C., P.H. Manríquez, G. Paradis, R.W. Day, J.C. Castilla, R.R. Warner, D.W. Lea, and S.G. Gaines. 2003. Trace elemental fingerprinting of gastropod statoliths to study larval dispersal trajectories. Marine Ecology Progress Series 248:297-303. 